\title{
Total UK multi-centre experience with a novel arterial occlusion device (Duct Occlud pfm)
}

\author{
A Tometzki, K Chan, J De Giovanni, A Houston, R Martin, D Redel, A Redington, \\ M Rigby, J Wright, $\mathrm{N}$ Wilson
}

\begin{abstract}
Objective-To report the total UK multicentre experience of a novel arterial occlusion device (Duct Occlud pfm).

Design-Descriptive study of selected non-randomised paediatric patients with a variety of aortopulmonary connections. Setting-Five UK tertiary referral centres for congenital heart disease.

Patients and methods-Between March 1994 and February 1995, 57 children aged 2 weeks to 14 years (median 50 months) underwent attempted closure of their aortopulmonary connection. Fifty one had persistent arterial ducts and 9 of them had had a Rashkind umbrella device implanted. Five patients had superfluous modified Blalock-Taussig shunts (mBTS). In one there was also a native major aortopulmonary collateral artery (MAPCA). Another patient had a native major aortopulmonary connection (APC). Transcatheter occlusion was attempted in all cases through a $4 \mathrm{~F}$ delivery catheter.
\end{abstract}

Results-Devices were successfully deployed in $49 / 57(86 \%)$ patients. Seven of 51 cases with persistent arterial ducts were judged too large for the device and a Rashkind umbrella was used. 40 (91\%) of the 44 in whom the detachable coil device was used had complete occlusion at 24 hours on colour flow Doppler echocardiography. Devices were successfully deployed in all 6 remaining patients (4 mBTS, 1 mBTS + MAPCA, and 1 APC). Embolisation of a device occurred on 4 occasions. Two devices were not retrieved but caused no apparent clinical problems. Conclusion-This novel detachable coil type occlusion system compares favourably with other methods of transcatheter occlusion of native, residual, or surgically created aortopulmonary shunts. The delivery system allows its use in small children.

(Heart 1996;76:520-524)

Keywords: aortopulmonary connections; detachable coil device; Duct Occlud pfm; congenital heart disease
Occlusion of unwanted aortopulmonary connections, whether they be native such as the persistent arterial duct or surgically created Blalock-Taussig shunts, are now achieved by a transcatheter procedure in many centres in the UK. Several devices designed to occlude the persistent arterial duct have been developed over the past three decades. They include the Porstmann Ivalon plug, the Rashkind double umbrella USCI device, and the adjustable button device of Sideris. ${ }^{1-3}$ All require relatively large delivery systems for implantation. Such devices have also been used to occlude Blalock-Taussig shunts. ${ }^{4}$ Single and multiple non-detachable occluding coils have recently been used to close persistent arterial ducts with good results. ${ }^{56} \mathrm{~A}$ new detachable coil device (Duct Occlud pfm) has recently been described. ${ }^{7}$ We reported the use of this new method to close superfluous Blalock-Taussig shunts. ${ }^{8}$ We report the total UK experience of using this new device for transcatheter occlusion of aortopulmonary connections.

\section{Patients and methods}

PATIENTS

Between March 1994 and January 1995, 57 children underwent cardiac catheterisation and attempted closure of their aortopulmonary connection with the Duct Occlud coil. They represent the total UK experience of this device during this period. Their median age was 50 months (range two weeks to 14 years) and median weight $15.6 \mathrm{~kg}$ (range 2.8 to $45.8 \mathrm{~kg}$ ). Fifty one patients had a persistent arterial duct and nine of these had had a Rashkind umbrella device implanted. In one patient an attempt to implant a Rashkind umbrella had failed. A further two patients had continuous murmurs after incomplete surgical ligation. Five of the remaining six patients had a modified Blalock-Taussig shunt (mBTS) which was now superfluous including one case with an additional residual major aortopulmonary collateral artery (MAPCA). The primary diagnosis for which the shunt was created included three patients with critical pulmonary stenosis, one case of tetralogy of Fallot, and one case of pulmonary atresia and ventricular septal defect. There was one patient, aged 14 years, with a native aortopul- 
Figure 1 (A) Long and (B) short axis view of configured device showing diabolo configuration.
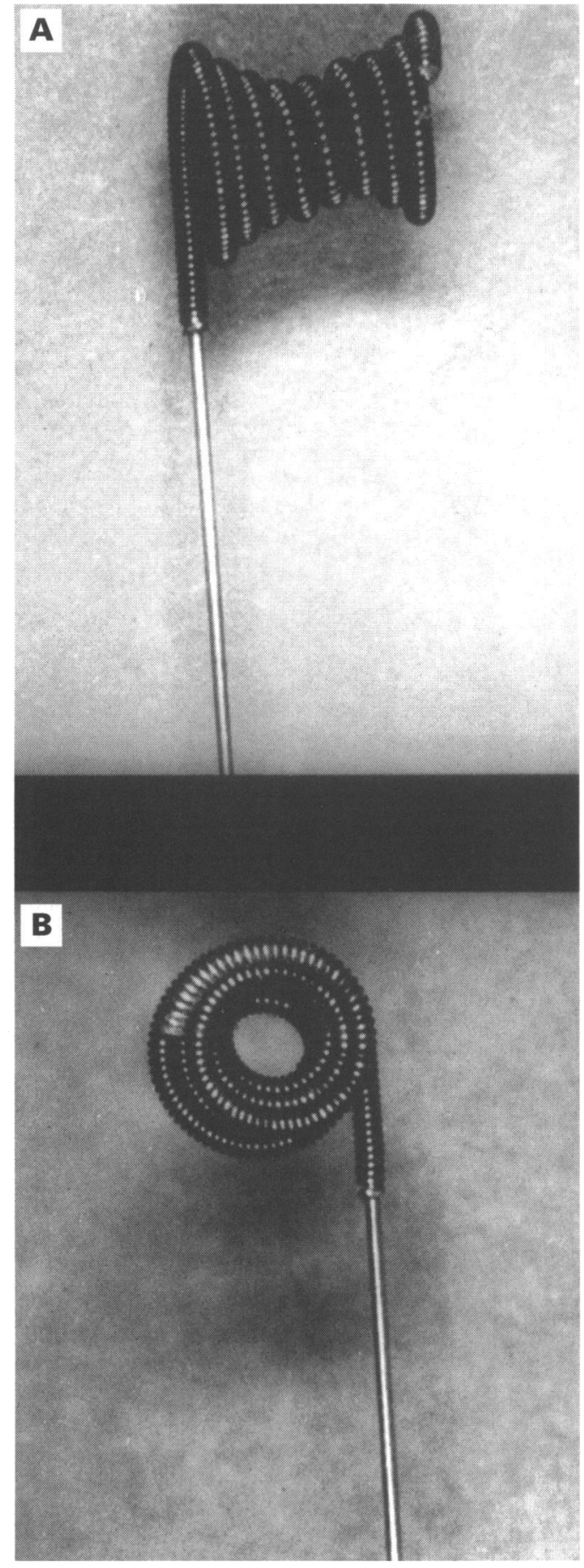

monary connection in the setting of pulmonary atresia with ventricular septal defect. Informed written consent was obtained in all cases from the patient or parent.

\section{PROCEDURE}

All procedures were performed under general anaesthesia. A 4F delivery catheter was used to deliver the device. The diagnosis was confirmed by clinical and echocardiographic examination. Transvenous occlusion was attempted in all cases of persistent arterial duct but a retrograde arterial approach was needed in five cases after difficulty was experienced in crossing the duct this way. An arterial route was used in the remaining six patients. Aortography was performed to delineate the anatomy and size of the lesion. This was aided by a $4 \mathrm{~F}$ pigtail graduated marker catheter in the proximal descending aorta. Antibiotic prophylaxis (intravenous cefuroxime $50 \mathrm{mg} / \mathrm{kg}$ ) was given at induction and two further doses were given at 8 hour intervals. The coil device (pfm Duct Occlud) complies with the European directives on implantable devices and with the requirements of the Department of Health for implantation of sterile medical devices and surgical products (registration no $\mathrm{RO} 434 / \mathrm{SP}$ ). It is mounted in a straightened profile on the distal end of a core wire to which it is secured by a snap-on mechanism and a circumferential groove. The proximal end of the core wire is covered by a moveable hollow wire which when moved proximally pushes the device off the core wire. As the device is pushed off the end of the core wire it takes on an hourglass or diabolo shape (fig 1). A number of coil configurations are available. Each has a known axial length and is available in different proximal and distal loop diameters with a central portion diameter of less than $2.5 \mathrm{~mm}$ when fully deployed. The device size is governed by the diameter of the ampulla of the duct in its mid-portion. The aim is to select a device with a maximum distal diameter 1 to $2 \mathrm{~mm}$ larger than the mid diameter of the ampulla. The largest device available is $7 \mathrm{~mm}$ and thus this limits the procedure to ducts with a minimum diameter of less than $4 \mathrm{~mm}$. In ducts of $4 \mathrm{~mm}$ or more the operator may experience pull through of the device. Occlusion rates are likely to be reduced and the risk of embolisation will almost certainly increase. The coil device system is advanced to the tip of the delivery catheter which is positioned in the descending aorta in the case of a persistent arterial duct. The core wire is withdrawn in a controlled fashion using the delivery handle. This ensures that a known number of windings of the device are used. Typically three or four windings are delivered and the device is withdrawn into the lesion. The core wire is withdrawn once more and further windings push out the end of the catheter. The operator aims to deliver a little less than half of the windings on the pulmonary artery side of the duct. At this stage the snap-on mechanism remains secure and allows complete retrieval should the operator wish. Final release is accomplished by a positively felt action of pushing the coil from the core wire. Repeat angiography is performed some minutes after deployment to assess the position of the device and the state of occlusion. Figures 2 and 3 show various key stages of the procedure. Two dimensional and colour flow mapping Doppler echocardiography is performed before discharge the following day.

\section{Results}

A single device was successfully deployed in 49 patients. In one patient, who had undergone surgery for pulmonary atresia and ventricular septal defect, two devices were implanted, one in a left mBTS and the other in a MAPCA. There were no serious complications during the procedure and no deaths. 
Figure 2 (A) Preprocedural lateral aortogram of a native arterial duct $(A O$, aorta $P A$, pulmonary artery. Arrow indicates arterial duct). (B) Proximal windings of the device deployed in the pulmonary artery used before release. (C) Device deployed and disconnected from delivery system. (D) Post-

procedural aortogram.
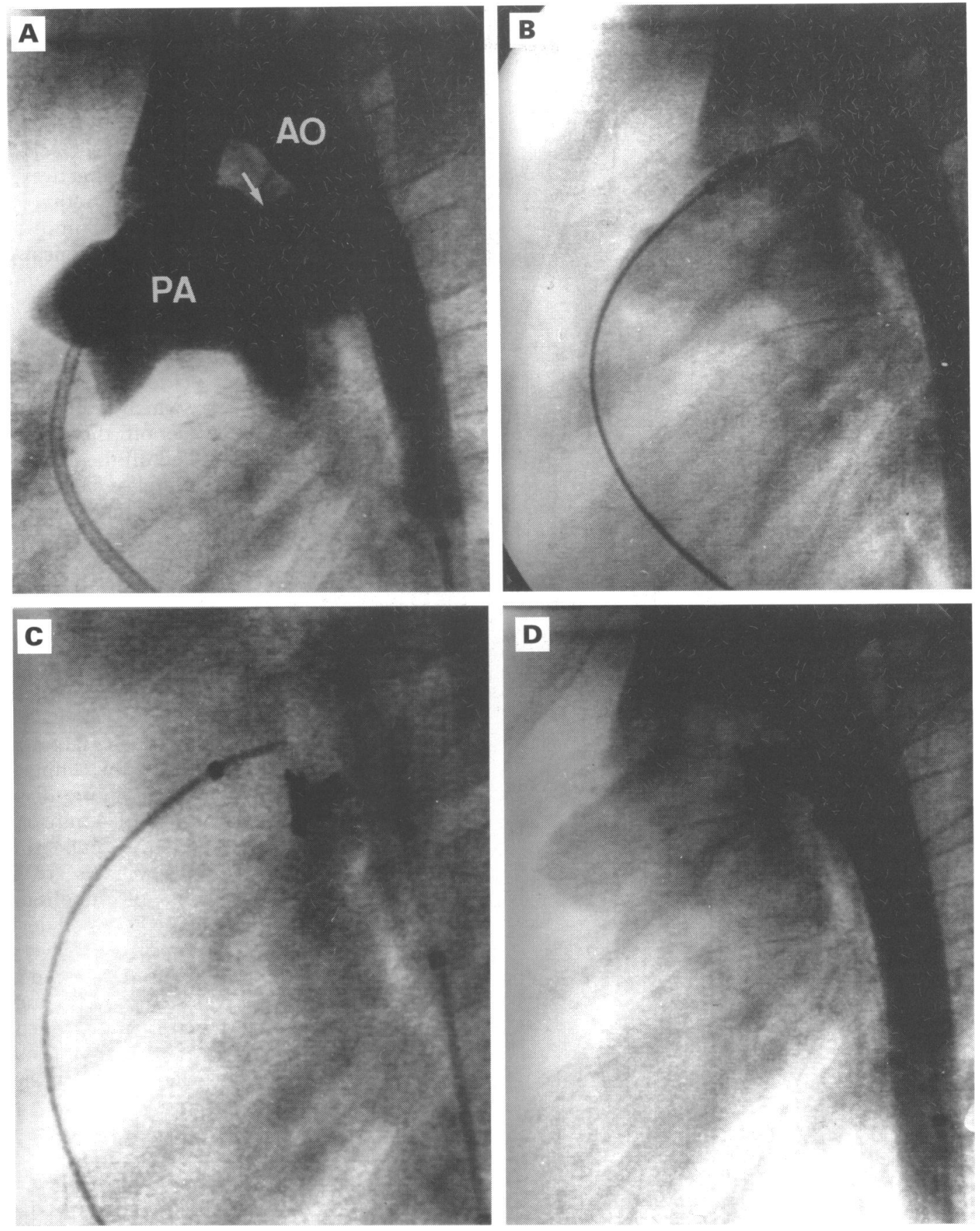

In one case a groin haematoma occurred while another patient had a transient loss of the peripheral pulse. Screening time for each procedure ranged from five to 40.5 minutes (median 18.9 minutes)

\section{PERSISTENT ARTERIAL DUCT}

A device was successfully implanted in $44 / 51$ $(86 \%)$. This was accomplished transvenously in 39 patients including three who required the formation of an arteriovenous loop to position the delivery catheter. In five patients the device was deployed via a transarterial route and with our later experience we would now tend to use this method rather than the more involved manipulation necessary to create an arteriovenous loop. The minimum diameter of native ducts in this series ranged from 1.0 to $4.3 \mathrm{~mm}$ (mean (SD) $2 \cdot 1(0 \cdot 8) \mathrm{mm}$ ). Seven of the 51 patients with a persistent arterial duct were judged to have a duct that was too large for the device and subsequently a Rashkind umbrella was used. These included a patient with marked dilatation of the duct after pull through of the device. In a further patient a device was implanted but electively removed without complication because its position was unsatisfactory. Embolisation of the device occurred in $3 / 51$ cases $(5.8 \%)$ : in one this was some hours after implantation and a further catheter procedure was required for its removal. In one individual the device could not be retrieved from a distal branch of the right pulmonary artery. In another a $3 \mathrm{~mm}$ fragment of a device became entangled in the tricuspid apparatus. This patient had another device successfully deployed and at 12 months follow up the fragment remained in situ with no evidence of tricuspid regurgitation or other clinical consequence. 


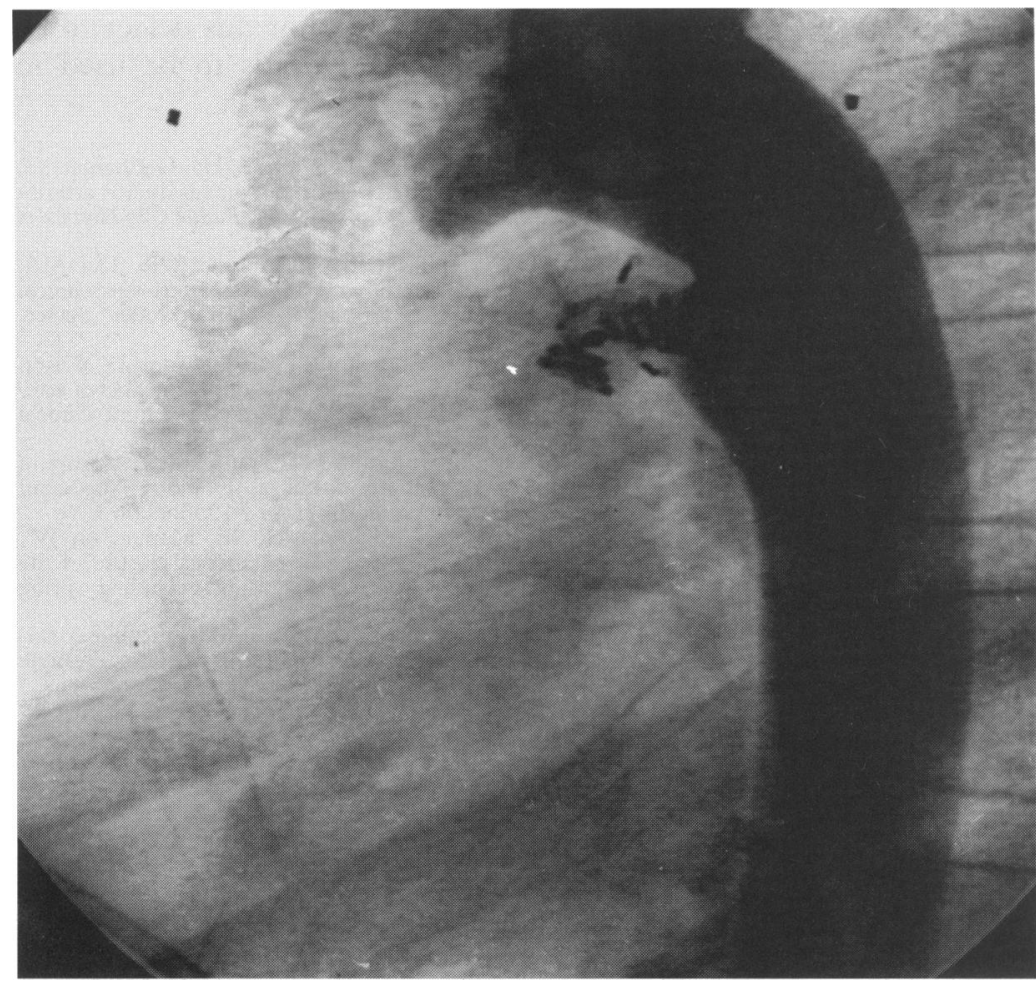

Figure 3 Device in situ over a previously implanted Rashkind umbrella device.
At 24 hours, colour flow Doppler echocardiography showed complete occlusion in $40 / 44$ patients $(91 \%)$. An increased Doppler velocity of $1.6 \mathrm{~m} / \mathrm{s}$ was found post procedure in the left pulmonary artery in one patient with a $5 \mathrm{~mm}$ device implanted in a $1.7 \mathrm{~mm}$ native duct.

There has been one late recanalisation of the duct through the centre of a device with the recurrence of a continuous murmur noted six months after implantation. The intention is that this patient will have a second device implanted.

\section{SURGICALLY CREATED AORTOPULMONARY SHUNTS}

Complete "on the table" occlusion was accomplished in four patients who had superfluous right $5 \mathrm{~mm}$ Gore-Tex mBTSs that had been created at two weeks, 11, 17, and 41 months of age. In these patients a $5 \mathrm{~mm}$ device was used in two cases, a $6 \mathrm{~mm}$ in one, and a $7 \mathrm{~mm}$ in the last. There was one embolisation of the device to a distal left upper lobe branch of the pulmonary artery. It could not be retrieved. Complete occlusion was achieved with a larger device at a separate procedure some days later: thus all five patients now have complete occlusion of their modified Blalock-Taussig shunt.

AORTOPULMONARY COLLATERAL

Complete occlusion of aortopulmonary collateral arteries in two patients was achieved immediately in one and evident at angiographic re-examination after six months.

\section{Discussion}

The persistent arterial duct and unwanted native or surgically created systemic to pulmonary connections are attractive lesions for transcatheter occlusion. This has led to the development of several devices including Ivalon plugs, umbrellas, buttons, and coils. ${ }^{16}$ The most widely used is the Rashkind double umbrella device but its large delivery sheath prevents its use in small children. A European Registry report described 686 patients in whom $94.8 \%$ had an umbrella implanted. ${ }^{9}$ Colour flow Doppler echocardiography performed at 24 hours showed complete occlusion in $53 \%$ of cases rising to $83 \%$ at one year. These results resemble those of Hosking et al who, excluding those who underwent implantation of a second device, reported a residual shunt of $11 \%$ at 40 month follow up. ${ }^{10}$ Our early occlusion rate of $91 \%$ at 24 hours compares favourably with these studies. The early occlusion rate was not improved by impregnating the Rashkind device with thrombin. ${ }^{11}$ We believe that the remaining $9 \%$ of our patients may have a natural progression to closure in time, as is the experience with other devices. We did, however, see one case of recanalisation during follow up and we intend to implant a second device in this patient. Late recanalisation has also been seen to occur with the Rashkind umbrella. ${ }^{12}$ This supports the approach of long-term follow up for all implanted devices.

There is concern that any device could encroach on the origin of the left pulmonary artery and lead to stenosis of this artery. This is particularly so with the $17 \mathrm{~mm}$ umbrella in small children. ${ }^{13}$ It seems most unlikely that a correctly placed device with a maximum diameter of $7 \mathrm{~mm}$ will obstruct this artery. Not withstanding the limitations of Doppler echocardiography in the assessment of left pulmonary artery stenosis we are confident that the one patient with a velocity of $1.6 \mathrm{~m} / \mathrm{s}$ in this area does not have stenosis.

The use of a single occluding coil technique was recently reported by Moore et al. ${ }^{5}$ The delivery of the coil into the duct was facilitated by a retrograde approach with a 5 or $5.5 \mathrm{~F}$ catheter. In this study the coils used formed a helix with a diameter of 3,5 , or $8 \mathrm{~mm}$. These coils are not attached to the delivery wire and the potential for embolisation with this method is obvious. Hijazi and Geggel reported an anterograde approach with single and multiple Gianturco coils through a $4 \mathrm{~F}$ delivery catheter. ${ }^{6} \mathrm{Up}$ to five coils were used: they ranged in diameter from 2 to $8 \mathrm{~mm}$. The coil embolised in three of 33 patients which is slightly more often than for duct implantation $(3 / 51)$, perhaps underlining the advantage of a controlled release mechanism.

The Duct Occlud pfm has the advantage of assuming a diabolo configuration on its release into the duct which in many cases it mimics in shape. ${ }^{7}$ Krichenko et al categorised the types of ductal anatomy and commented on the difficulties that may be encountered particularly with the tubular ductus. ${ }^{14} \mathrm{We}$ 
agree with this statement because in our first case the duct was tubular and previous attempts at occlusion with Gianturco coils had resulted in embolisation. The advantage of this new device is that it remains fully retrievable therefore allowing its removal and re-implantation if a satisfactory position is not at first obtained. Because the embolisations in this series occurred during the first 33 cases they may be a consequence of the learning curve for the procedure. There were several operators in this series, however. It was not possible to retrieve an embolised device in two patients. The small diameter of the devices does make distal retrieval more difficult. In the event of non-retrieval, however, it seems unlikely that there will be significant loss of perfusion to a lung as a consequence, unless this complication occurs in a small child. The smallest of our patients in whom an embolised device could not be retrieved weighed $9.8 \mathrm{~kg}$. There have been no clinical sequelae. Failure to retrieve Gianturco coils and the Rashkind umbrella device has been reported. ${ }^{59}$

The use of occlusion devices to close other systemic to pulmonary connections has been well described. ${ }^{415} \mathrm{We}$ have recently reported our success with the closure of two modified Blalock-Taussig shunts. ${ }^{8}$ Since that report our experience with more patients has proved the efficacy of the device.

Transcatheter occlusion of aortopulmonary connections whether they be native, residual, or surgically created can be achieved effectively and safely with this new detachable device. The inability to proceed in seven patients with native persistent arterial ducts may be overcome by developing a range of larger diameter devices. The small size of the delivery system allows it to be used in infants weighing less than $3 \mathrm{~kg}$. For this device to be evaluated more fully it needs to be used in larger studies.

1 Portsmann W, Wierny L, Warnke H, Gertberger G, Romaniuk PA. Catheter closure of patent ductus arteriosus, 62 cases without thoracotomy. Radiol Clin North Am 1971;9:201-13.

2 Rashkind WJ, Mullins CE, Hellenbrand WE, Tait MA. Non-surgical closure of patent ductus arteriosus: clinical pplication of the Rashkind PDA occluder device. Circulation 1987;75:583-92.

3 Rao PS, Sideris EB, Haddad J, Rey C, Hausdorf G, Wilson $\mathrm{AD}$, et al. Transcatheter occlusion of patent ductus arteriosus with adjustable buttoned device. Initial clinical experience. Circulation 1993;88:1119-26.

4 Houde C, Zahn EM, Benson LN. Transcatheter closure of Blalock-Taussig shunts with a modified Rashkind
a umbrella delivery system. Br Heart $\mathcal{F}$ 1993;69:56-8.

5 Moore JW, George L, Kirkpatrick SE, Mathewson JW, Spicer RL, Uzark K, et al. Percutaneous closure of the small patent ductus arteriosus using occluding spring coils. $千$ Am Coll Cardiol 1994;23:759-65.

6 Hijazi Z, Geggel RL. Results of antegrade trancatheter closure of patent ductus arteriosus using single or multiple coils. Am f Cardiol 1994;74:925-9.

7 Le TP, Neu MB, Redel DA, Weinzheimer HR. A new transcatheter occlusion technique with retrievable, double-disk shaped coils-first clinical results in occlusion of patent ductus arteriosus (abstract). Cardiol Young 1993;3:I-38.

8 Tometzki AJP, Houston AB, Redington AN, Rigby ML Redel DA, Wilson N. Closure of Blalock-Taussig shunts using a new detachable coil device. Br Heart $\mathcal{F}$ 1995;73: using a

9 Report of the European Registry. Transcatheter occlusion of persistent arterial duct. Lancet 1992;240:1062-6.

10 Hosking MC, Benson LN, Musewe N, Dyck JD, Freedom RM. Transcatheter occlusion of the persistently patent ductus arteriosus. Circulation 1991;84:2313-7.

11 Vitiello R, Benson L, Musewe N, Freedom R. Factors influencing the persistence of shunting within 24 hours of catheter occlusion of the ductus arteriosus. Br Heart $f$ 1991;65:211-2.

12 Bjornstad PG, Smevik B. Recanalization of the arterial duct after initial total occlusion with the Rashkind umbrella. Cardiol Young 1995;5:98-9.

13 Gatzoulis MA, Rigby ML, Redington AN. Umbrella occlusion of the persistent arterial duct in children under two sion of the persistent arterial duct
years. Br Heart $\mathcal{f} 1994 ; 72: 364-7$.

14 Krichenko A, Benson LN, Burrows P, Moes CAF, Mclaughlin P, Freedom RM. Angiographic classification of the isolated, persistently patent ductus arteriosus and implications for percutaneous catheter occlusion. $\mathrm{Am} \mathscr{f}$ Cardiol 1989;67:877-80

15 Redington AN, Rigby, ML. Novel uses of the Rashkind ductal umbrella in adults and children with congenita heart disease. Br Heart $\mathcal{F}$ 1993;69:47-51. 